\title{
SPINAL CORD INJURIES IN DOGS PART II: STANDARDS OF CARE, PROGNOSIS AND NEW PERSPECTIVES
}

\author{
Šulla, I. ${ }^{1}$, Balik, V. ${ }^{2}$, Horňák, S. ${ }^{3}$, Ledecký, V. ${ }^{3}$ \\ ${ }^{1}$ Department of Anatomy, Histology and Physiology \\ ${ }^{3}$ Small Animal Clinic, University of Veterinary Medicine and Pharmacy, Komenského 73, 04181 Košice \\ Slovakia \\ ${ }^{2}$ Institute of Molecular Medicine and Translational Medicine \\ University Hospital and Faculty of Medicine and Dentistry, Palacky University, I. P. Pavlova 6, 77220 Olomouc \\ Czechia
}

igor.sulla@uvlf.sk

\section{ABSTRACT}

Severe spinal cord injuries (SCI), causing physical handicaps and accompanied by many serious complications, remains one of the most challenging problems in both, human and veterinary health care practices. The central nervous system in mammals does not regenerate, so the neurological deficits in a dog following SCI persists for the rest of its life and the affected animals display an image of permanent suffering. Diagnostics are based on: neurological examination, plain $x$-rays of vertebral column, $x$-rays of the vertebral column following intrathecal administration of a water-soluble contrast medium (myelography), $x$-rays of the vertebral column following epidural administration of a contrast medium (epidurography), computed tomography (CT) and/or magnetic resonance imaging (MRI). Currently, only limited therapeutic measures are available for the dogs with SCIs. They include: the administration of methylprednisolone sodium succinate (MPSS) during the acute stage; early spinal cord decompression; stabi- lisation of vertebral fractures or luxations; prevention and treatment of complications, and expert rehabilitation. Together with the progress in the understanding of pathophysiologic events occurring after SCI, different therapeutic strategies have been instituted, including the local delivery of MPSS, the utilisation of novel pharmacological agents, hypothermia, and stem/precursor cell transplantation have all been tested in the experimental models and preclinical trials with promising results. The aim of this review is the presentation of the generally accepted methods of diagnostics and management of dogs with SCIs, as well as to discuss new therapeutic modalities. The research strategy involved a PubMed, Medline (Ovid), Embase (Ovid) and ISI Web of Science literature search from January 2001 to December 2017 using the term "spinal cord injury", in the English language literature; also references from selected papers were scanned and relevant articles included.

Key words: dog; diagnostics; new perspectives; spinal trauma; therapy 


\section{INTRODUCTION}

The principal composition and function of the central nervous system (CNS) in dogs, cats, pigs and primates are similar $[7,8,14,16,22,31]$. The spinal cord injuries (SCIs) naturally occur ing these species, but the regeneration of neurons within their brain and spinal cord is limited [68]. The neurological symptomatology, complication rate and their character may be also similar, and the treatment options and the prognosis resemble the situation in people [2, $14,22,31,47,58,77]$. The same diagnostic and therapeutic measures are utilised in both, human and veterinary medicine $[6,19,29,53,64,69]$. That is why the authors decided to review recently published papers relating to canine spinal trauma and inform the health care professionals about the generally accepted methods and new achievements, ready to be tested in preclinical and clinical trials.

\section{DIAGNOSTICS}

The trauma patients may suffer significant damage not only to the vertebral column, but also to other body systems. These accompanying injuries may pose more immediate threats to their lives than the damage to the spinal cord. So when evaluating an animal with a neurologic deficit due to a suspected trauma, it is necessary to assess the overall stability of the organism, i. e. function of pulmonary and cardiovascular systems in the first place, then proceed with careful examination of the entire nervous system [9, $12,14,45]$. The clinical experience has shown that traumatic brain lesions, especially in their mild forms, accompany different traumatic events quite often, and multilevel cord damage is also possible $[53,67]$. A theoretical progression of clinical symptomatology is as follows: pain-ataxia-paresis_plegia — and the loss of deep pain sensations [67]. The simple scales recommended for primary, informative assessment of spinal cord functions applicable in dogs are the Tarlov grading system and the American Spinal Injury Association impairment scale, i.e. ASIA scale [12, 31, 40, 53, 64]. More details are in Table 1. The plegia and loss of deep pain sensations are very important indicators of severe spinal cord lesions. They are usually associated with the damage to the significant parts of the white matter, while dogs that are only painful and ataxic, likely have only restricted spinal cord involvement $[12,69,75]$.

\begin{tabular}{lll}
\hline Grade 0 & - & Complete paralysis (tetra- or paraplegia) \\
& & with no extremity function \\
Grade 1 & - & Minor joint movements \\
Grade 2 & - & Major joint movements \\
Grade 3 & - & Animal can stand \\
Grade 4 & - & Animal can walk \\
Grade 5 & - & Animal can climb a $20^{\circ}$ inclined plane
\end{tabular}

However, there are symptoms, which help to localise the spinal cord lesion in a dog more precisely (Table. 2).

Table 2. Neurological symptoms related to localisation of a spinal cord lesion [14, 48, 77]

\begin{tabular}{cl}
\hline $\begin{array}{c}\text { Lesion } \\
\text { localization }\end{array}$ & \multicolumn{1}{c}{ Clinical findings } \\
\hline $\mathrm{C} 1-\mathrm{C5}$ & $\begin{array}{l}\text { Crossed extensor reflex in all } 4 \text { extremities, neck pain, } \\
\text { Horner syndrome, proprioceptive deficits } 4 \mathrm{x} \text {, increased } \\
\text { myotatic reflexes } 4 \mathrm{x} \text {, increased tone } 4 \mathrm{x}, \text { tetraparesis/ } \\
\text { tetra-plegia, increased tone, upper motor neuron uri- } \\
\text { nary bladder }\end{array}$ \\
\hline
\end{tabular}

C6-Th2 Absent cutaneous trunci reflex, neck pain, decreased thoracic limb tone/withdrawal reflexes, pelvic limb crossed extensor reflexes, back pain, proprioceptive deficits $4 \mathrm{x}$, Horner syndrome, tetraparesis/tetraplegia, increased pelvic limb myotatic reflexes, upper motor neuron urinary bladder, increased pelvic limb tone

Th3 - L3 Absent cutaneous trunci reflexes near level of lesion, paraparesis/paraplegia, pelvic limb crossed extensor reflexes, back pain, proprioceptive deficits in pelvic limbs, increased pelvic limb myotatic reflexes, upper motor neuron urinary bladder, increased pelvic limb tone

L4-S3 Lumbosacral pain, decreased anal tone/reflex, lower motor neuron urinary bladder, decreased pelvic limb myotatic reflexes, decreased pelvic limb tone/withdrawal reflexes, paraparesis/paraplegia, pelvic limb proprioceptive deficits, limp tail

L4-S3 Lumbosacral pain, decreased anal tone/reflex, lower motor neuron urinary bladder, decreased pelvic limb myotatic reflexes, decreased pelvic limb tone/withdrawal reflexes, paraparesis/paraplegia, pelvic limb proprioceptive deficits, limp tail

Legend: $4 \mathrm{x}$ - in all four extremities; $\mathrm{C}$ - cervical

Th-thoracic; L-lumbar; $S$ - sacral

\section{Imaging diagnostic techniques}

Röntgenological investigations are still crucial in determining an accurate diagnosis of spinal pathology [9, 30]. Plain radiographs, sometimes in different projections (ventro-dorsal, lateral, oblique) are especially helpful in identifying bone abnormalities, such as luxations and/or 


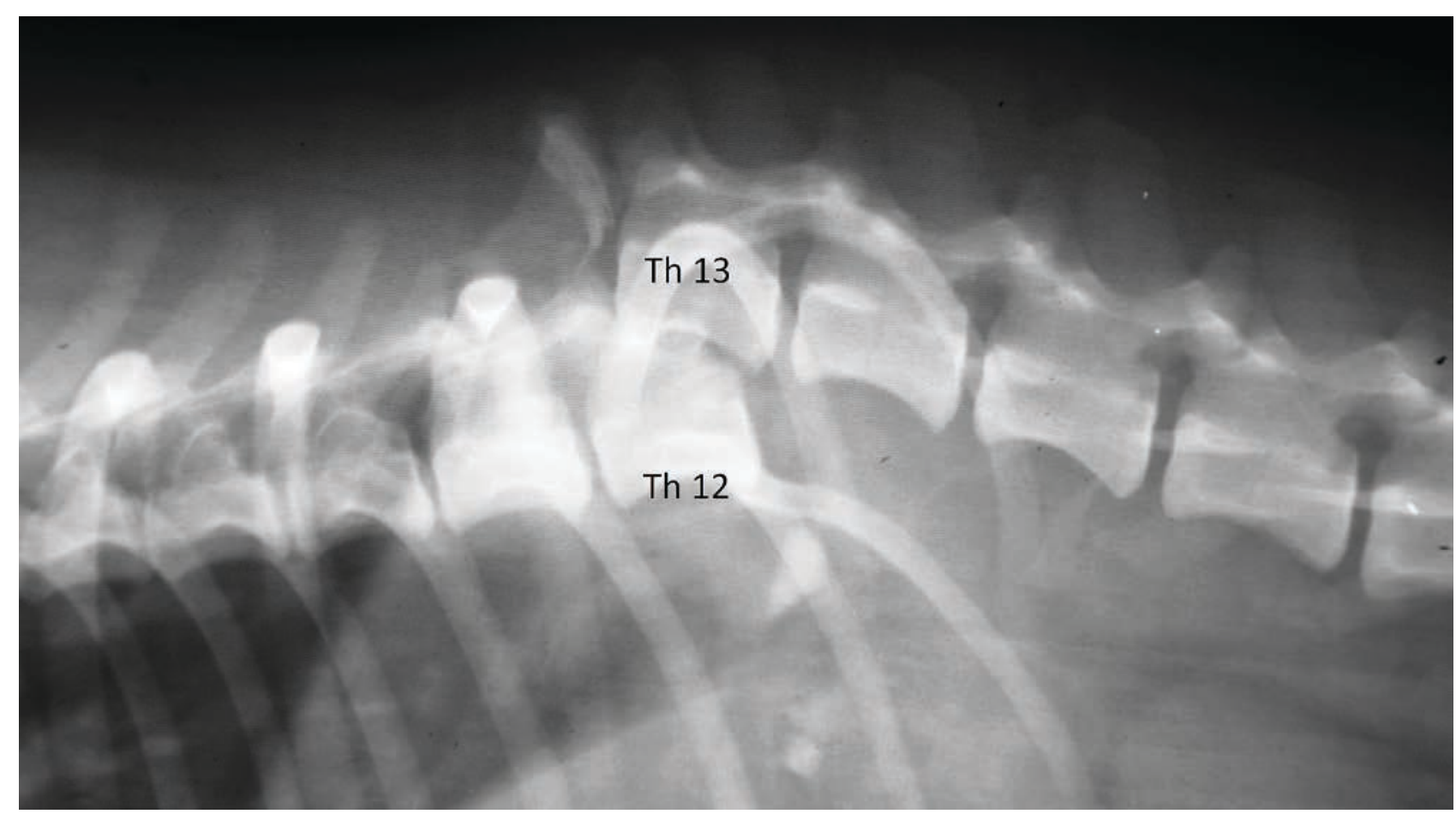

Fig. 1. Plain röntgenogram of a dog with fracture-luxation Th12/Th13 vertebrae; lateral projection

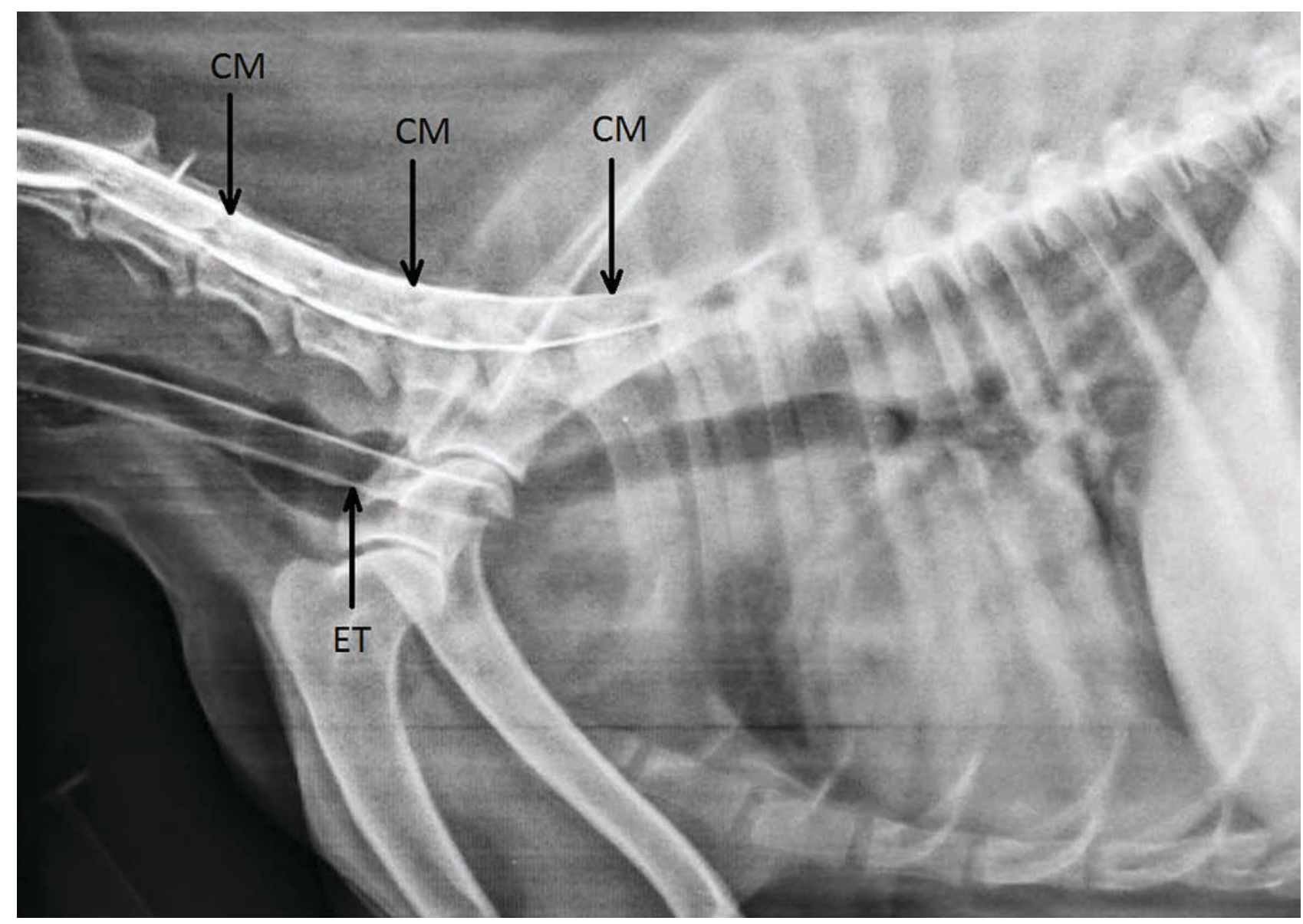

Fig. 2. An example of contrast $x$-ray examination (myelography) of cervical and cranial part of thoracic spinal canal in a dog; lateral projection. The procedure was performed under general endotracheal anaesthesia $\mathrm{CM}$ - contrast medium; ET - endotracheal tube 


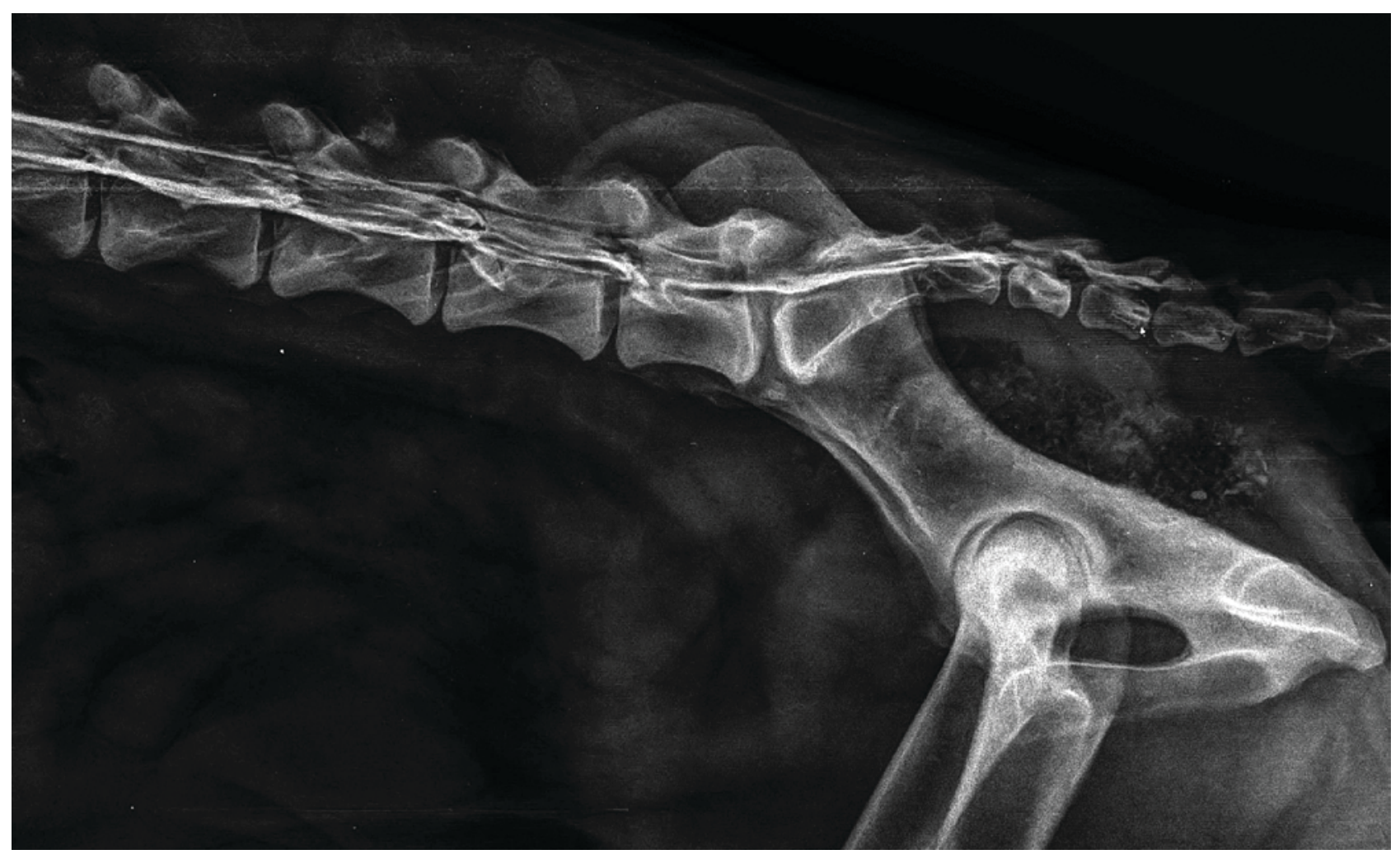

Fig. 3. An example of a contrast $x$-ray examination of the lumbosacral region of the vertebral canal (epidurography) in a dog; lateral projection
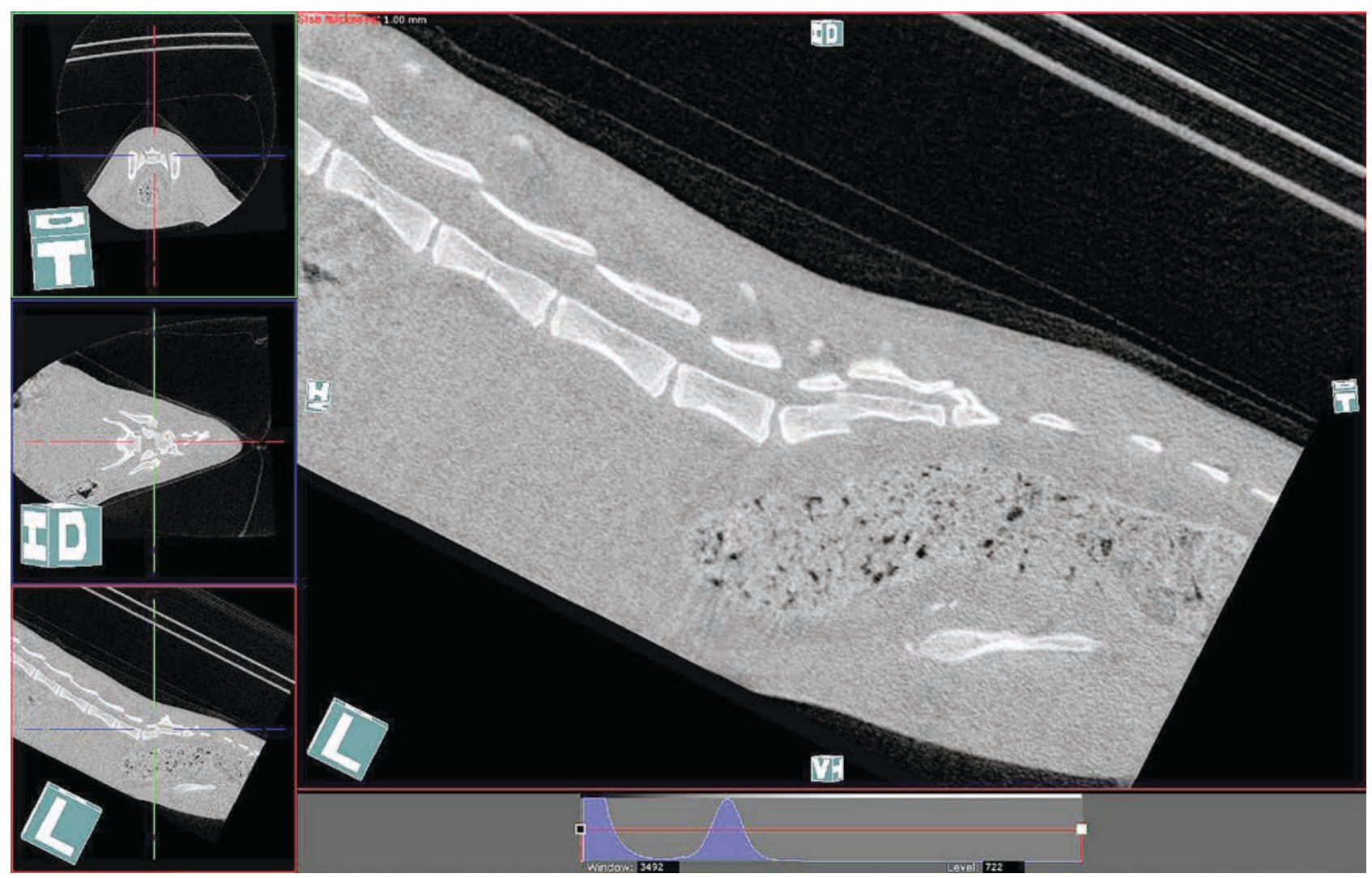

Fig. 4. A CT examination of a dog with a sacral bone fracture causing the traumatic cauda equina syndrome. Obstipation developed due to anal sphincter hypertone $\mathrm{T}$ - transversal plane; $\mathrm{D}$ - dorsal plane; $\mathrm{L}$ - lateral plane 


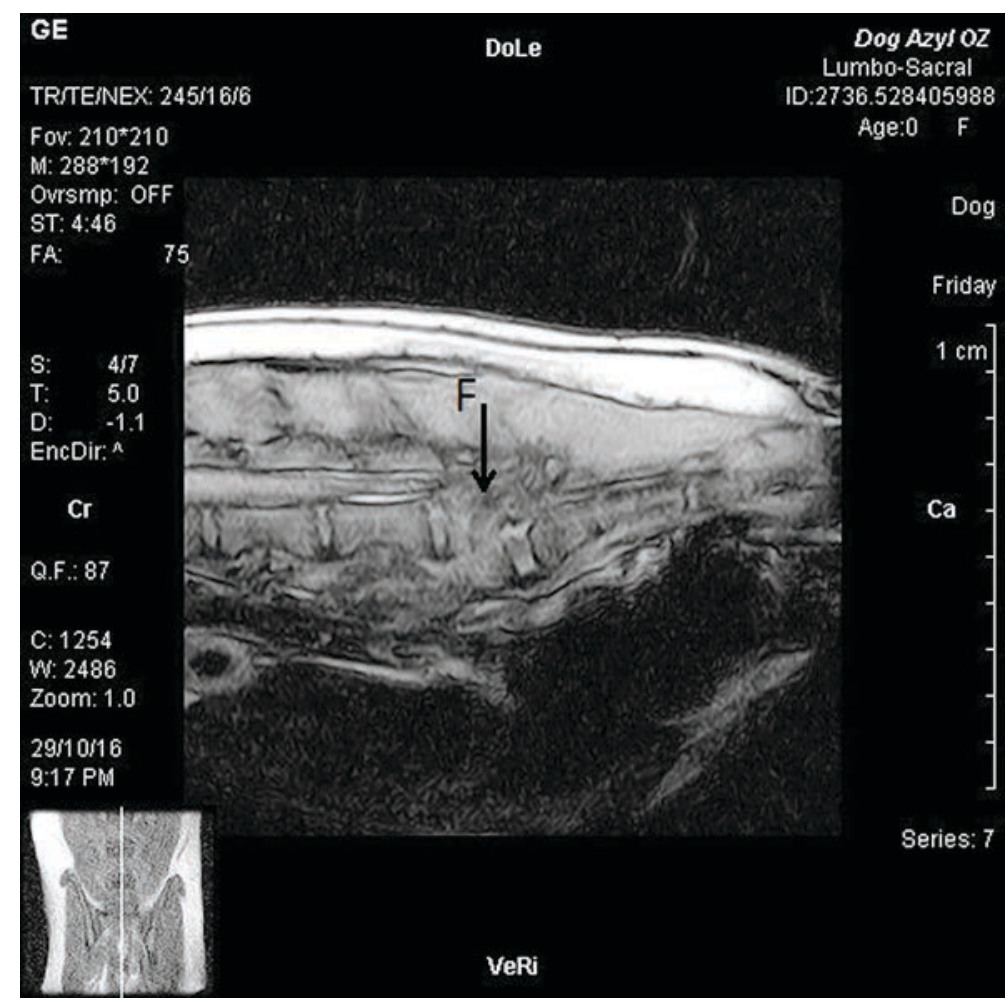

Fig. 5. A MRI examination (T2-weighted image) of a dog with a fracture of L7 vertebra, traumatic conus medullaris syndrome, intra- as well as a paraspinal haematoma of the soft tissues. F - fracture

fractures of vertebrae; sometimes they are able to show narrowing of the intervertebral space, which is an indirect sign of intervertebral disc disease (IVDD) [7,63].

It is necessary to stress, that negative plain $\mathrm{x}$-rays do not exclude vertebral column or spinal cord injury. That is why advanced diagnostic techniques, e.g. myelography (x-rays following administration of water-soluble contrast medium into the spinal dural sack), epidurography (x-rays following the administration of water-soluble contrast medium into the spinal epidural space), comput ed tomography (CT scan) and magnetic resonance imaging (MRI), are more frequently used nowadays $[49,55]$. The CT scans provide much greater details of the bony structures and are able to show the extent of any encroachment on the spinal canal by vertebral displacements or bone fragments. MRI gives information about the spinal cord and soft tissues. This imaging technique is able to reveal the cause of the cord compression, whether from bone, prolapsed discs, ligamentous damage, or instraspinal haematomas [75]. CT and MRI are the best available diagnostic tools currently.

\section{Differential diagnosis}

Several non-traumatic spinal cord lesions can cause the symptomatology of tetra- or paraplegia/tetra- or paraparesis [28]. The most important of them are:

1. Fibrocartilaginous embolism (FCE) is encountered in dogs quite frequently $[10,21]$. It occurs when material from the nucleus pulposus of the intervertebral disc forms an embolus that obstructs vessels within the spinal medulla. FCE commonly affects dogs of large or giant breeds [75]. Dogs typically present with a peracute neurologic deficits that progress for about 24 hours. The neurological symptomatology can be asymmetric and dogs are usually painless $[21,75]$. To establish a definitive diagnosis of FCE it is possible only by the help of histopathologic examination, which shows fibrocartilaginous emboli within the spinal cord vasculature identical to the nucleus pulposus [10, $21,75]$. Perimyelography or CT scans can be used to make a presumptive diagnosis, but the best antemortem diagnostic tool is MRI currently [75]. Different treatment modalities (e.g. administration of steroids) for FCE have been 
attempted, but no significant positive effects have been found. So the treatment of FCE is conservative, usually it includes rest, followed by physical therapy [10, 20, 21, 57].

2. Spinal epidural or subdural bleeding - are rare pathological events in dogs. Clinical presentation is characterised by a sudden pain in a specific region of the spine (depending on the affected part of the body axis) accompanied by neurological deficits progressing to tetra- or paraplegia $[12,53]$. This clinical entity can occur after light falls, jumps, or excessive training, but sometimes may even occur spontaneously. For the localisation and extent of the suspected haematoma, it helps to assess perimyelography; however, to establish the exact diagnosis it is possible only by the help of CT scans. This menacing situation may be solved by an urgent surgical revision and removal of the blood clot $[53,77]$.

3. Spinal epidural abscess or subdural empyema. They occur rarely, in the majority of the cases accompany meningitis or different purulent processes. The patient has fever and symptoms of meningeal irritation. Perimyelography helps the diagnostics, but CT or MRI are preferable. In the treatment of an urgent surgical revision, evacuation of pus, bacteriological identification of the microorganisms and prolonged administration of antibiotics are recommended [28].

4. Viral (Herpes simplex virus, Varicella-zoster virus, Cytomegalovirus, Tick encephalo-myelitis virus), fungal (Cryptococcus spp.) or parasitic (Toxoplasma gondii, Schistosoma mansoni) transverse myelitis can develop in dogs. Infectious agents mostly enter the spinal medulla by haematogenous transit (from a distant focus) or directly in the time of penetrating injuries or surgical interventions. The perimyelography helps to exclude spinal cord compression, and MRI is able to verify myelitis. The exact diagnosis is dependent on bacteriological and serological tests $[28,30]$.

5. Many pathological conditions occurring in dogs may produce clinical symptoms that mimic SCI. The diagnostic problems may appear in neurological diseases such as: the Wobbler syndrome, the canine distemper, degenerative myelopathy, tick paralysis, toxoplasmosis and polyradiculoneuropathy [12].

6. Wobbler syndrome is a common cervical problem. It occurs especially in Great Danes and Doberman Pinschers. The clinical symptomatology is caused by compression of the cervical spinal cord by the vertebral malformation-malarticulation of C5, C6, and C7. The onset is usually insidi- ous with signs which are normally progressive, but sometimes acute. Owners generally recognise ataxia of the pelvic limbs. Dogs often cross, abduct or collapse on walking and turning. The animal gives an impression that it does not know where its limbs are because of a proprioceptive deficit. The thoracic limb signs (if present) are similar, but less marked [12].

7. Canine distemper (hardpad disease) is caused by a single-stranded RNA virus of the family Paramixoviridae. The disease impacts several body systems, including gastrointestinal and respiratory tracts, but acts predominantly on the spinal cord. Canine distemper is highly contagious and fatal in about $50 \%$ of the cases [12]. Dogs younger than 1 year are especially suspect of having the disease. The affected animal reveals signs of segmental myelopathy with progressive neurological deficits. An example is mild thoracic limb deficit in a paraplegic dog. Quite often additional symptoms (e.g. head tilt, nystagmus, head tremor, nasal and ocular discharge, harsh lung sounds, hyperkeratosis of the nose and foot pads, chorioretinopathy and myoclonus) may be seen. There is no specific treatment for the disease. The prevention is vaccination [12].

8. Degenerative myelopathy $(\mathrm{DM})$ is a progressive disease with no specific cure. Currently it is suspected that $\mathrm{DM}$ is an immune-mediated illness resembling Multiple sclerosis (MS) in humans. It occurs predominantly in aging German Shepherds and is characterised by a slowly progressive paraparesis and ataxia of the pelvic limbs. The onset is insidious and may continue for five to six months. Proprioception is the first affected function, along with crossed limbs and hyperreflexia of the pelvic extremities. Symptomatology may be asymmetrical. The neurological deficit is caused by diffuse degeneration of the myelin sheaths and neural axons in both ascending and descending tracts of the spinal cord. The peripheral nerves may be involved too, resulting in the lower motor neuron signs. The diagnosis is based on: the breed of the dog, its age, typical history, clinical symptomatology and exclusion of other intraspinal lesions. The myelography, CT and MRI negate compression of neural structures, and the CSF examinations are normal [12].

9. Tick paralysis is caused by a neurotoxin produced in the tick's salivary gland. Clinical presentation begins with paresis, hyporeflexia and ataxia five to seven days after the attachment of the tick and the symptomatology can progress to paralysis with areflexia. Finding ticks on the 
dog helps to establish the diagnosis. The CSF examination is normal, however the neurotoxin reduces nerve conduction velocity, the amplitude of muscle action potentials and causes a total blockade of transmission at the myoneural junctions [30]. Following the removal of the tick, the neurological deficit subsides $[12,30]$.

10. Toxoplasmosis can cause various clinical signs. They include seizures, blindness, tremor, hemi- or paraparesis, and hindquarter paralysis. Spinal reflexes may be absent and extensor rigidity present in one or both pelvic extremities. The history is usually of a young dog showing gradual progressive paralysis. A positive diagnosis is difficult, but serology may be of some help [12].

11. Polyradiculoneuropathy (coonhound paralysis). The etiology of this disease is unknown. The functional lesion is on the ventral nerve roots and peripheral nerves. The disease is initiated by raccoon bites one to two weeks before the onset of any clinical signs. The majority of the affected dogs show paresis and hyporeflexia of the pelvic limbs and dysphonia. The neurological deficits progresses to tetraplegia with areflexia, while the animal demonstrates alertness and has a normal temperature. Adult hunting dogs are most commonly affected [12].

\section{SPINAL TRAUMA MANAGEMENT}

It is very important to have an initial assessment aimed at identifying all of the imminently life-threatening injuries. The basic $\mathrm{ABC}$ examination (the patency of the airways, the ability of the dog to breathe, and the effectiveness of circulation) is recommended $[9,14,31,67]$. Most animals with significant traumatic events will present a state of hypovolemic shock due to inappropriate vasodilation, blood loss, or both. Hypovolemia and hypoxemia can contribute to secondary spinal cord damage, so rapid correction of perfusion deficit is of paramount importance. In dogs with a systolic blood pressure less than $90 \mathrm{mmHg}$ require aggressive fluid resuscitation $[9,53]$. The administration of synthetic colloids (e.g. "Dextran-70" 10-20 ml.kg-1 over 15-20 min, or hypertonic saline $4-5 \mathrm{ml} . \mathrm{kg}^{-1}$ over $15-20 \mathrm{~min}$ ) are indicated for hypovolemic shock. Dehydrated trauma victims should receive isotonic crystalloids (e.g. lactated "Ringer's solution" or $0.9 \%$ saline). In animals unresponsive to fluid therapy, vasopressor agents (e.g. dopamine $5-12 \mu \mathrm{g} \cdot \mathrm{kg}^{-1} \mathrm{~min}^{-1}$ or epinephrine infusion $1-10 \mu \mathrm{g} \cdot \mathrm{kg}^{-1} \mathrm{~min}^{-1}$ ) should be used to maintain adequate systemic blood pressure $[9,13,29$, 53]. Hyperoxygenation is recommended for most trauma patients. Dogs who are conscious should be administered supplemental oxygen via nasal cannulae or nasal oxygen catheters. The face masks tend to stress dogs, so they should only be used temporarily. Animals with airway obstruction or SCIs causing hypoventilation should be intubated and ventilated $[29,53,69]$.

\section{Specific therapy for spinal trauma}

While there are significant differences between humans and non-primate animals in terms of supraspinal motor control of extremities, the basic brainstem-spinal control systems for walking are similar [2, 65, 70, 76]. More importantly, cellular mechanisms (activation of microglia, apoptosis, axonal sprouting, and inhibition effects within adult CNS) do not differ $[3,13,22,32,38,42,58,62,68$, $72,73,76]$

Once the diagnosis of a traumatic SCI has been made and the location of the lesion and the cause of medullary damage has been established, a decision must be made concerning what type of treatment will be pursued. Basically, it is determined by the personal opinion of the veterinary surgeon and the choice of the owner $[9,53,55,63]$. Vertebral fractures and luxations may be treated conservatively (e.g. by a strict rest for 2-6 weeks and/or immobilization using external braces, supplemented by administration of analgesics, anti-inflammatory drugs and physical therapy). However, the surgical methods, i. e. decompression, reposition of fragments and internal fixation are more and more frequently preferred nowadays, since the literature provides strong evidence, that the early surgical decompression is associated with better recovery at 6 months after the event as defined by a 2-grade improvement in the grading system (impairment scale) modified for dogs [9, 31, 40, 52, 63]. Surgical management is generally recommended when: the dog has preserved only minimal voluntary motor function or is completely paraplegic; there is a clinical or radiographic evidence of unstable vertebral fracture/luxation; or the neurologic deficit is progressing despite an appropriate conservative management $[9,52,77]$.

The first proven pharmacological treatment for SCI in humans was introduced in the 1990s $[6,29]$. In a multicentre clinical study, a high dose of the synthetic corticosteroid methylprednisolone (MPSS) was reported to reduce disability when administered within $8 \mathrm{~h}$ of trauma. MPSS 
reduces swelling, glutamate release, free-radical accumulation, upregulates anti-inflammatory factors, and decreases oxidative stress $[35,73]$. According to the Cochrane review, the MPSS treatment should be started by a $30 \mathrm{mg} \cdot \mathrm{kg}^{-1}$ bolus within the first 3 hours after injury and continued by $5.4 \mathrm{mg} \cdot \mathrm{kg}^{-1} \cdot \mathrm{h}^{-1}$ for 24 hours. [6]. On the other hand, the treatment with a high-dose of MPSS is associated with serious complications (e.g. gastric bleeding, wound infections, myopathy) outweighing potential benefit for neurological improvement $[20,56,66]$. That is why a local delivery of MPSS to the epicentre of the injury is currently being tested $[32,34,35]$. The majority of patients following SCIs are in the chronic phase of their disease. With an aim to help them, different neuroregenerative proceedings are being experimentally tested $[31,33,35,70]$.

A critical part of any treatment for SCI is an effective rehabilitation strategy. It is aimed to reduce chronic complications (e.g. pressure ulcers, spasticity, and development of deformities) and enhance residual functions [1, 19, 40, 74]. The physical rehabilitation improves muscle tone and mobility, activates preserved intramedullary circuits, maintains existing neural cell connections, promotes synaptogenesis, myelination and neurite sprouting, i.e. it is able to raise the physical as well as emotional condition of the patient $[9,19,26]$. That is why the more advanced rehabilitation procedures are recommended in the treatment of dogs with SCIs $[31,53,63]$.

\section{Complications}

The most frequent complications connected with SCIs in dogs are: neuropathic pain, problems with the evacuation of the urinary bladder, spasticity, pressure ulcers and sexual incompetence.

Two thirds of humans with SCI report pain and about a third of them rate their pain as severe. It is reasonable to assume about the same occurrence of post-injury chronic pain syndromes in animals also. Pain can be at the level of the injury, or it can be experienced in other areas, where sensation is usually limited or absent. Neuroscientists suppose that at-level pain results from damage to spinal cord one or more segments cranial to the lesion, whereas pain caudally from the lesion can result from the interruption of axon pathways, the formation of abnormal connections within the spinal cord and/or functional changes in neurons, which make them hyperexcitable. Consequently, a more aggressive treatment in the first few hours after in- jury could limit the secondary damages and reduce the development of chronic pain syndromes following SCIs [10, $14,20,54]$.

The majority of patients with post traumatic tetra- or paraplegia are not able to control voiding and suffer with recurrent urinary tract infections due to bladder over distension and urine stagnation $[12,48]$. The treatment consists of regular urinary bladder evacuation and administration of antibiotics. There are two types of problems with bladder evacuation - the upper motor neuron (UMN) dysfunction and the lower motor neuron (LMN) dysfunction [12, 48]:

a) The UMN bladder dysfunction is caused by spinal cord lesions between the pons and the L7 segment. The hallmark of this lesion is interference with the detrusor reflex and hyperactivity of the urethral musculature. The bladder fills with urine, but the dog is not able to urinate. Upon palpation, the bladder is turgid and it is difficult to express the urine manually. The intermittent catheterization can solve the problem $[12,48]$.

b) The LMN bladder dysfunction occurs with lesions of the sacral spinal cord or nerves of the lumbosacral plexus. The hallmark of the LMN bladder dysfunction is decreased tone of both, detrusor as well as urethral musculature. This lesion attenuates or abolishes the detrusor reflex and the dog constantly dribbles urine; decreased or absent perineal reflexes and sensation accompany the condition. The application of light abdominal pressure easily evacuate urine $[12,48]$.

About $60 \%$ of animals following SCIs suffer with spasticity. Recent studies indicate that the loss of descending tracts results in the decreased activity of inhibitory interneurons. It causes the over reaction of moto neurons to excitatory stimuli $[1,12,53]$. If spasticity appears in paraplegic dogs, medical therapy (administration of drugs acting within the CNS - baclofen, diazepam or directly on skeletal muscles - dandrolene) is recommended. In spasticity resistant to pharmacological interventions, there is severing of the reflex pathways (surgical rhizotomy or myelotomy) [1].

Dogs with paraplegia due to SCI, its chronic comorbidities, impaired autonomic innervation as well as protective sensory perception are particularly vulnerable to developing pressure sores - pressure ulcers (decubitus). They also are at high risk for the occurrence of recurrent ulcers which can be life-threatening as a potential source of infections and sepsis. The pressure ulcer is defined as a soft tissue damage resulting from prolonged pressure over bony prominences 
resulting in ischemia and necrosis [36]. The pathological sequelae of pressure can be reversed at the ischemic stage if pressure and supportive factors (e. g. shear, friction and/or moisture) are excluded. So changing the position of paraplegic animal (every 2 hours) and the removal of supportive factors are effective preventive measures $[37,53]$. There are four clinical stages of pressure ulcers. The sores of stage 1 and 2 positively react to the relief of pressure, debridement of necrotic skin and subcutaneous fat, control of bacterial colonization, and nutrition supplementation; the ulcers of stage 3 demand surgical excision and tissue reconstruction. The best solution for dogs with deep necrosis involving bones, joints and tendons (stage 4) is euthanasia. The decision of therapeutic interventions depends on the attitude and financial situation of the owner $[9,14,24,37,63]$.

Dogs afflicted with SCI reveal two types of sexual problems. The tetra-, or paraparesis/tetra- or paraplegia hinders or excluded copulatory activities, i. e. mounts and intromission in males, lordosis in females [48]. The severe SCI disrupts the reflex mediated increase in genital blood flow (required for engorgement of erectile tissues in males and vasocongestion of clitoris, vaginal wall, and lubrication of the vaginal surface in females). Even if the sympathetically mediated arousal is intact, the males have problems to maintain erection and suffer a retrograde (intravesical) ejaculation, due to incompetence of the internal urethral sphincter [48]. As a result, male reproductive function is significantly affected. On the contrary, the female dogs with SCI are able to become pregnant, as well as undergo normal pregnancy and delivery [48].

\section{PROGNOSIS}

Dogs with tetraplegia due to the lesion of the cervical spinal cord have a poor prognosis. Many of them perish before any therapeutic intervention is available or they are euthanized immediately after the incident. The financial burdens of tetraparetic animal's treatment also are rather high, so the majority of owners prefer an early euthanasia.

1. In paraparetic/paraplegic dogs with intervertebral disc herniation (Hansen type 1 disc disease) but intact perception, a decompressive operation (hemilaminectomy or laminectomy and removal of the disc fragments from the vertebral canal) is indicated as soon as possible. Following an active therapy, they can recover completely, their prog- nosis is considered favourable with surgery [7, 27, 40, 46, 53]. Hansen type 1 disc herniation accompanied by loss of deep pain sensation (lack of nociception), the prognosis is less favourable. Decompressive surgery can help to regain nociception and the ability to ambulate without assistance in about $60 \%$ of the deep pain negative dogs $[55,63]$. Dogs with paraparesis due to the intervertebral disc protrusion but intact nociception have a favourable prognosis with conservative management. The decompressive operation is not indicated; animals make significant improvements and are ambulatory with medical treatment only $[7,53]$.

2. Dogs with vertebral instability due to fracture and/or luxation, paraplegia and lack of nociception have a poor prognosis. The surgical revision, decompression of neural structures and stabilisation of vertebral column is recommended (it helps to start an early rehabilitation programme), however results are dubious, so many owners prefer euthanasia $[9,31,53]$. A much better prognosis is in animals with vertebral fractures and/or luxations accompanied with intact sensations. Early surgical decompression and stabilisation are indicated $[9,31]$.

3. Clinical observations show that the prognosis in patients with spinal cord syndromes are significantly more favourable than in patients with tetra- or paraplegia [26]. As far as recovery of motor function is concerned, the best outcome was observed in patients with Brown-Séquard syndrome - 75-90\% of them were able to ambulate independently following long-term rehabilitation [26]. On the other hand, the anterior spinal cord syndrome has a poor prognosis with only a $10-20 \%$ chance of functional recovery, and even in those with some improvement, the muscle power is significantly impaired and coordination of movements is insufficient $[26,47]$. Patients with posterior spinal cord syndrome have preserved muscle strength, temperature and pain sensation, but lost proprioceptive and vibration sense caudally to the level of the spinal cord lesion. They generally show the least favourable recovery from impaired perception. They are able to ambulate, but with a tendency to falls $[26,47]$. The cauda equina syndrome has a better prognosis for neurological recovery than SCIs because nerve roots are able to regenerate. The most important predictors for a favourable outcome are early diagnosis and surgical decompression [26, 47].

\section{Prognosis for dogs with fibrocartilaginous embo-}

lism is generally favourable; the majority of patients will show recovery of some functions within 2 weeks of me- 
dicament treatment, but maximal improvement may take several months $[21,29]$. The surgical intervention is not indicated. The negative prognostic factor is lack of nociception $[53,57,75]$.

\section{NEW TRENDS IN SCI MANAGEMENT}

It is well known, that brain and spinal cord tissue does not regenerate. That is why the management of SCI in humans and domestic animals is currently targeted at preservation of remaining functions and prevention of complications. However, multiple experimental studies performed on different laboratory animals brought at least partially positive results, when therapeutic measures concentrated on:

1. The suppression of a secondary injury cascade by: the administration of a sodium-channel blocker "riluzole"; central nervous system stromal cells, antibiotic with antiinflammatory properties (including inhibition of tumour necrosis factor- $\alpha$, i.e. TNF- $\alpha$, interleukin $1 \beta$, i.e. IL- $1 \beta$, cyclooxygenase-2, nitric oxide synthase, i. e. NOS) and microglial activation "minocyclin"; systemic or local mild hypothermia $\left(33-34^{\circ} \mathrm{C}\right)$; more accurate delivery of intravenously injected MPSS bond to ferromagnetic nanoparticles to the epicentre of the lesion by help of a magnet placed on exposed dura mater through laminectomy, which reduces the risk of serious side effects of the methylprednisolone $[3,22,23,25,29,35,37,41,43,58,59,71]$, so all of these things may prove to be helpful. Clinical utilisation of hypothermia is still controversial, since the systemic hypothermia is often accompanied by serious complications and its results are not unequivocally positive. Obviously, the systemic hypothermia is too complex of a procedure for veterinary practice. So local hypothermia by cold saline applied through laminectomy during the operation together with potential administration of methylprednisolone seem to be the most promising method for dogs and cats with acute SCIs $[6,14,23]$. The clinical utilisation of different strategies and pharmacological agents mentioned in previous texts are considered experimental therapy, so far.

2. The suppression of spinal cord cell necrosis by the application of "fibroblast growth factor" i.e. FGF or "curcumine" (protect against excitotoxic cell death and mitigate oxygen free radical production); or antiapoptotic molecules i.e. "valproic acid", "vitamin E", “17 $\beta$-estradiol”, "melatonine" [27, 37-39, 41, 53, 60, 72].
3. Restraining of axon demyelination or supporting their remyelination by cellular therapy $[5,18,33,44,51,61,70]$.

4. Suppression of axon growth and regeneration inhibiting proteins expression [15, 44, 69, 71]. Significant therapeutic opportunities offer the utilisation of endogenous and exogenous repair mechanisms, as well as drugs suppressing the activation of axonal sprouting inhibitors, e. g. chondroitin sulfate proteoglycans, CSPGs, myelinassociated glycoproteins, MAGs, oligodendrocyte-myelin glycoprotein, OMGP, and neurite outgrowth inhibitor-A, NOGO-A, acting on receptors associated with the RhoROCK pathway, directly able to inhibit neurite growth. In rat experimental models monoclonal antibodies against CSPGs, MAGs, OMGP and Nogo-A significantly improved regeneration of damaged spinal cords $[5,15,33,44,71]$. Alongside of a direct inhibition of Rho-ROCK pathway, another therapeutic modality was discovered. The enzyme chondroitinase ABC (Ch-ABC) degrades CSPGs in the glial scar and effectively removes initiators of the Rho-ROCK cascade. In rodent models of SCI, intrathecal or intraparenchymal administration of $\mathrm{Ch}-\mathrm{ABC}$ reduced the expression of CSPGs as well as scar and cavity volume [11, 37, 71].

5. Support of physiologic production or administration of guiding molecules directing axonal growth to the target structures $[4,8,17,29,33,50,61,70]$.

6. Generation of bridges in post traumatic intramedullary cysts and syringomyelic cavities providing support and protection for regenerating axons by chitozan microtubules and/or transplanted progenitor/stem cells [4, 51, 58, 71].

7. Production of regenerative molecules by transplanted precursor/stem cells obtained from autologous bone marrow, fat tissue, olfactory bulbs, olfactory fibres or ensheathing (Schwann) cells $[8,51,61,69,70]$.

8. Autotransplantation of modified mesenchymal precursor/stem cells harvested from adult bone marrow or fat tissue and expanded in cell cultures to neural, oligodendritic or astrocytic lines, which are potentially able to replace damaged spinal cord tissues [3, 18, 33, 50, 51, 61, 70].

\section{CONCLUSION}

This review provides an overview of the current information on canine spinal cord injuries, their treatment, imply new therapeutic options, and discusses new trends in SCI research. 


\section{ACKNOWLEDGEMENTS}

The accumulation and study of literature dealing with different aspects of the spinal cord injuries as well as the preparation of our paper was supported by the grant for the Agency of the Ministry of Education, Science, Research and Sport of the Slovak Republic for the Structural Funds of EU, ITMS 26220220127 and VEGA grant No. 1/0898/15. The authors are grateful to Silvia Ficova, DVM from SIBRA, Centre for Veterinary Medicine, Bratislava, Slovakia for providing the $\mathrm{CT}$ and MRI scans.

\section{REFERENCES}

1. Adams, M. M., Hicks, A. L., 2005: Spasticity after spinal cord injury. Spinal Cord, 43, 577-586.

2. Akhtar, A. Z., Pippin, J. J., Sandusky, C. B., 2008: Animal models in spinal cord injury: a review. Rev. Neurosci., 19, 47-60.

3. Badner, A., Vawda, R., Laliberte, A., Hong, J., Mikhail, M., Jose, A., et al., 2016: Early intravenous delivery of human brain stromal cells modulates systemic inflammation and leads to vasoprotection in traumatic spinal cord injury. Stem Cells Transl. Med., 5, 991-1003.

4. Bockurt, G., Mothe, A.J., Zahir, T., Kim, H., Shoichet, M.L., Tator, C. H., 2010: Chitosan channels containing spinal cord-derived stem/progenitor cells for repair of subacute spinal cord injury in the rat. Neurosurgery, 67, 1733-1744.

5. Borrie, S. C., Baeumer, B. E., Badtlow, C. E., 2012: The nogo66 receptor family in the intact and diseased CNS. Cell Tissue Res., 349, 105-117.

6. Bracken, M.B., 2012: Steroids for acute spinal cord injury. Review. Cochrane Database Syst. Rev., 1, Art. No.: CD001046.

7. Brisson, B. A., 2010: Intervertebral disc disease in dogs. Vet. Clin. North Am. Small Anim. Pract., 40, 829-858.

8. Brock, J., Rosenzweig, W. E., Blesch, A., Moseanko, R., Havton, L., Edgerton, V., et al., 2012: Local and remote growth factor effects after primate spinal cord injury. J. Neurosci., 30, 9728-9737.

9. Bruce, C. W., Brisson, B. A., Gyselinck, K., 2008: Spinal fracture and luxation in dogs and cats: a retrospective evaluation of 95 cases. Vet. Comp. Orthop. Traumatol., 21, 280-284.

10. Cauzimille, L., Kornegay, J. N., 1996: Fibrocartilaginous embolism of the spinal cord in dogs: Review of 36 histologically confirmed cases and retrospective study of 26 suspected cases. J. Vet. Intern. Med., 10, 241-245.
11. Devaux, S., Cizkova, D., Quamico, J., Franck, J., Nataf, S., Pays, L., et al., 2016: Proteomic analysis of the spatio-temporal based molecular kinetics of acute spinal cord injury identifies a time- and segment-specific window for effective tissue repair. Moll. Cell. Proteomics, 15, 2641-2670.

12. Dewey, C.W., 2008: A Practical Guide to Canine and Feline Neurology. 2nd edn., Iowa State University Press, Ames, Iowa, USA, $706 \mathrm{pp}$.

13. Dumont, R. J., Okonkwo, D. O., Verma, S., Hurlbert, R. J., Boulos, P.T., Ellegala, D. B., et al., 2001: Acute spinal cord injury, Part I: Pathophysiologic mechanisms. Clin. Neuropharm., 24, 254-264.

14. Eminaga, S., Palus, V., Cherubini, G. B., 2011: Acute spinal cord injury in the cats: causes, treatment and prognosis. J. Feline Med. Surg., 13, 850-862.

15. Filbin, M. T., 2003: Myelin-associated inhibitors of axonal regeneration in the adult mammalian CNS. Nat. Rev. Neurosci., 4, 703-713.

16. Fletcher, T.F., 2013: Spinal cord and meninges. In Evans, H.P., de Lahunta, A., (Eds.): Miller's Anatomy of the Dog. 4th edn., Elsevier, Saunders, St. Louis, USA, 589-610.

17. Fouad, K., Ghosh, M., Vavrek, R., Tse, A.D., Pearse, D.D., 2009: Dose and chemical modification considerations for continuous cyclic AMP analog delivery to the injured CNS. J. Neurotrauma, 26, 733-740.

18. Fraga, J. S., Silva, N. A., Lourenco, A.S., Gincalves, V., Neves, N.M., Reis, R.L., et al., 2013: Unveiling the effects of the secretome of mesenchymal progenitors from the umbilical cord in different neuronal cell populations. Biochimie, 95, 2297-2303.

19. Frood, R.T., 2011: The use of treadmill training to recover locomotor ability in patients with spinal cord injury. Biosci. Hor., 4, 108-117.

20. Galandiuk, S., Raque, C., Appel, S., Polk, jr., H.C., 1993: The two-edged sword of large-dose steroids for spinal cord trauma. Ann. Surg., 218, 419-427.

21. Gandini, G., Cizinauskas, S., Lang, J., Fatzer, R., Jaggy, A., 2003: Fibrocartilaginous embolism in 75 dogs: clinical findings and factors influencing the recovery rate. J. Small Anim. Pract., 44, 76-80.

22. Gedrova, S., Galik, J., Marsala, M., Zavodska, M., Pavel, J., Sulla, I., 2018: Neuroprotective effect of local hypothermia in a computer-controlled compression model in minipig: correlation of tissue sparing along the rostro-caudal axis with neurological outcome. Exp. Therap. Med., 15, 254-270.

23. Grulova, I., Slovinska, L., Nagyova, M., Cizek, M., Cizkova, D., 2013: The effect of hypothermia on sensory-motor func- 
tion and tissue sparing after spinal cord injury. Spine J., 13, 1881-1891.

24. Haisma, J.A., van der Woude, L.H., Stam, H.J., Bergen, M.P., Sluis, T.A., Post, M.W., et al., 2007: Complications following spinal cord injury: occurrence and risk factors in a longitudinal study during and after in patient's rehabilitation. J. Rehab. Med., 39, 393-398.

25. Hanseobout, R.R., Hansebout, C. R., 2014: Local cooling for traumatic spinal cord injury: outcomes in 20 patients and review of literature. J. Neurosurg. Spine, 20, 550-561.

26. Harkema, S. J., Schmidt-Read, M., Lorenz, D. J., Edgerton, V.R., Behrman, A.L., 2012: Balance and ambulation improvements in individuals with chronic incomplete spinal cord injury using locomotor training-based rehabilitation. Arch. Phys. Med. Rehabilit., 93, 1508-1511.

27. Henke, D., Vandevelde, M., Doher, M.G., Stockli, M., Forterre, F., 2013: Correlations between severity of clinical signs and histopathological changes in 60 dogs with spinal cord injury associated with acute thoracolumbar intervertebral disc disease. Vet. J., 198, 70-75.

28. Hess, C. W., 2005: Nicht-traumatische akute Querschnittsyndrome. Praxis (Basel), 94, 1151-1159.

29. Hulbert, R.J., Hadley, M.N., Walters, B.C., Aarabi, B., Dhall, S.S., Gelb, D. E., et al., 2013: Pharmacological therapy for acute spinal cord injury. Neurosurgery, 72, 93-105.

30. Ilkiv, J.E., Turner, D. M., Howlett, C. R., 1987: Infestations in the dog by the paralysis tick Ixodes holocyclus. 1. Clinical and histological findings. Aust. Vet. J., 64, 137-139.

31. Jeffery, N.D., Hamilton, L., Granger, N., 2011: Designing clinical trials in canine spinal cord injury as a model to translate successful laboratory interventions into clinical practice. Vet. Rec., 168, 102-107.

32. Jeong, S. Y., Seol, D. W., Li, F. C., Chen, Q. X., 2008: The role of mitochondria in apoptosis. BMB Reports, 41, 11-22.

33. Kabu, S., Gao, Y., Kwon, B.K., 2015: Drug delivery, cell based therapies, and tissue engineering approaches for spinal cord injury. J. Control. Rel., 219, 141-154.

34. Kakulas, B. A., 2004: Neuropathology: the foundation for new treatments in spinal cord injury. Spinal Cord, 42, 549-563.

35. Kim, Y. T., Caldwell, J. M., Bellamkonda, R. V., 2009: Nanoparticle-mediated local delivery of methylprednisolone after spinal cord injury. Biomaterials, 30, 2582-2590.

36. Kruger, E. A., Pires, M., Ngann, Y., Sterling, M., Rubay, S., 2013: Comprehensive management of pressure ulcers in spinal cord injury: current concepts and future trends. J. Spin. Cord Med., 36, 572-585.
37. Kwon, B. K., Okon, E., Hillyer, J., Mann, C., Baptiste, D., Weaver, L. C., et al., 2011: A systematic review of non-invasive pharmacologic neuroprotective treatments for acute spinal cord injury. J. Neurotrauma, 28, 1545-1588.

38. Lee, J. Y., Kim, H.S., Choi, S. Y., Oh, T.H., Ju, B. G., Yune, T. Y., 2012: Valproic acid attenuates blood-spinal cord barrier disruption by inhibiting matrix metalloproteinase- 9 activity and improves functional recovery after spinal cord injury. J. Neurochem., 121, 818-829.

39. Lee, J. Y., Choi, S. Y., Oh, T. H., Yune, T. Y., 2012: $17 \beta$-estradiol inhibits apoptotic cell death of oligodendrocytes by inhibiting Rhoa-JNK3 activation after spinal cord injury. Endocrinology, $153,3815-3827$.

40. Levine, G. J., Levine, J. M., Budke, C. M., Kerwin, S. C., Au, J., Vinayak, A., et al., 2009: Description and repeatability of a newly developed spinal cord injury scale for dogs. Prev. Vet. Med., 89, 121-127.

41. Lin, M.S., Lee, Y.H., Chiu, W.T., Hung, K.S., 2011: Curcumin provides neuroprotection after spinal cord injury. J. Surg. Res., 166, 280-289.

42. Liu, W. M., Wu, J. Y., Li, F. C., Vhen, Q.X., 2011: Ion channel blockers and spinal cord injury. J. Neurosci. Res., 89, 791-801.

43. Lo, T. P., Cho, K. S., Garg, M. S., Lynch, M. P., Marcillo, A. E., Koivisto, D. L., et al., 2009: Systemic hypothermia improves histological and functional outcome after cervical spinal cord contusion in rats. J. Comp. Neurol., 514, 433-448.

44. Low, K., Culbertson, M., Bradke, F., Tessier-Lavigne, M., Tuszynski, M.H., 2008: Netrin-1 is a novel myelin-associated inhibitor to axon growth. J. Neurosci., 28, 1099-1108.

45. Mack, E. H., 2013: Neurogenic shock. Open Ped. Med. J., 7 (Suppl. 1: M4), 16-18.

46. McKee, W. M., Downes, C. J., Pink, J. J., Gemmill, T. J., 2010: Presumptive exercise-associated peracute thoracolumbar disc extrusion in 48 dogs. Vet. Rec., 166, 523-528.

47. McKinley, W., Santos, K., Meade, M., Brooke, K., 2007: Incidence and outcomes of spinal cord injury clinical syndromes. J. Spinal Cord Med., 30, 215-224.

48. McMurray, G., Casey, J.H., Naylor, A.M., 2006: Animal models in urologic disease and sexual dysfunction. Br. J. Pharm., 147, S52-S79.

49. Nakamoto, Y., Ozawa, T., Katanabe, K., Nishiya, K., Yasuda, N., Mashita, T., et al., 2009: Fibrocartilaginous embolism of the spinal cord diagnosed by characteristic clinical findings and magnetic resonance imaging in 26 dogs. J. Vet. Med. Sci., 71, 171-176.

50. Nakano, R., Edamura, K., Sugiya, H., Narita, T., Oka- 
bayashi, K., Moritomo, T., et al., 2013: Evaluation of mRNA expression levels and electrophysiological function of neuronlike cells derived from canine bone marrow stromal cells. Am. J. Vet. Res., 74, 1311-1320.

51. Nishida, H., Nakayama, M., Tanaka, H., Kitamura, M., Hatoya, S., Sugiura, K., et al., 2011: Evaluation of transplantation of autologous bone marrow stromal cells into the cerebrospinal fluid for treatment of chronic spinal cord injury in dogs. Am. J. Vet. Res., 72, 1118-1123.

52. Noble, L. J., Donovan, F., Igarashi, T., Goussev, S., Werb, Z., 2002: Matrix metalloproteinases limit functional recovery after spinal cord injury by modulation of early vascular events. J. Neurosci., 22, 7526-7535.

53. Olby, N., 2010: The pathogenesis and treatment of acute spinal cord injuries in dogs. Vet. Clin. N. Am. Small Anim. Pract., $40,791-807$

54. Ormond, D. R., Peng, H., Zeman, R., Das, K., Murali, R., Jhanwar-Uniyal, M., 2012: Recovery from spinal cord injury using naturally occurring anti-inflammatory compound curcumin: laboratory investigation. J. Neurosurg. Spine, 16, 497-503.

55. Penning, V., Platt, S. R., Dennis, R., Capello, R., Adams, V., 2006: Association of spinal cord compression seen on magnetic resonance imaging with clinical outcome in 67 dogs with thoracolumbar intervertebral disc extrusion. J. Small Anim. Pract., 47, 644-655.

56. Quian, T., Guo, X., Levi, A. D., Vanni, S., Shebert, R. T., Sipski, M.L., 2005: High-dose methylprednisolone may cause myopathy in acute spinal cord injury patients. Spinal Cord, 43, 199-203.

57. Risio, L.D., Platt, S.R., 2010: Fibrocartilaginous embolic myelopathy in small animals. Vet. Clin. North Am. Small Anim. Pract., 40, 859-869.

58. Rowland, J.W., Hawryluk, G.W.J., Kwon, B., Fehlings, M. G., 2008: Current status of acute spinal cord injury pathophysiology and emerging therapies: promise on the horizon. Neurosurg. Focus, 25, E2.

59. Saganova, K., Orendacova, J., Cizkova, D., Vanicky, I., 2008: Limited minocycline neuroprotection after ballooncompression spinal cord injury in the rat. Neurosci. Letters, $433,246-249$.

60. Samantaray, S., Das, A., Thakore, N.P., Matzelle, D.D., Reiter, R. J., Ray, L. K., et al., 2009: Therapeutic potencial of melatonin in traumatic central nervous system injury. J. Pineal Res., 47, 134-142.

61. Sarmento, C. A. P., Rodrigues, M.N., Bocabello, R.Z., Mess, A. M., Miglino, M.A., 2014: Pilot study: bone marrow stem cells as a treatment for dogs with chronic spinal cord injury. Reg. Med. Res., 2, 9.

62. Silva, N. A., Sousa, N., Reis, R. L., Salgado, A. J., 2014: From basics to clinical: a comprehensive review on spinal cord injury. Progr. Neurobiol., 114, 25-57.

63. Srugo, I., Aroch, I., Christopher, M.M., Chai, O., Goralnik, I., Bdolah-Abram, I., et al., 2011: Signs and outcome in acute nonambulatory thoracolumbar disc disease in dogs. J. Vet. Intern., Med., 25, 846-855.

64. Steward, O., Popovich, P. G., Dietrich, W.D., Kleitman, N., 2012: Replication and reproducibility in spinal cord injury research. Exp. Neurol., 233, 597-605.

65. Šulla, I., Balik, V., Petrovičová, J., Almášiová, V., Holovská, K, Oroszová, Z., 2016: A rat spinal cord injury experimental model. Folia Veterinaria, 60, 41-46.

66. Tsao, T. Y., Chen, E. L., Tsai, W.C., 2009: Steroids for acute spinal cord injury: revealing silent pathology. Lancet, 374 (9688), 500

67. Waters, R. L., Adkins, R. H., Yakura, J. S., 1991: Definition of complete spinal cord injury. Spinal Cord, 29, 573-581.

68. Webb, A. A., Ngan, S., Fowler, D. J., 2010: Spinal cord injury I: a synopsis of the basic science. Can. Vet. J., 51, 485-492.

69. Webb, A. A., Ngan, S., Fowler, D. J., 2010: Spinal cord injury II: prognostic indicators, standards of care, and clinical trials. Can. Vet. J., 51, 598-604.

70. Wewetzer, K., Radtke, C., Kocsis, J., Baumgärtner, W., 2011: Species-specific control of cellular proliferation and the impact of large animal models for the use of olfactory ensheathing cells and Schwann cells in spinal cord repair. Exp. Neurol., 229, 80-87.

71. Wilson, J.R., Foergione, N., Fehlings, M. G., 2013: Emerging therapies for acute traumatic spinal cord injury. Canad. Med. Assoc. J., 71, 281-299.

72. Wu, K. L. H., Hsu, C., Chan, J. Y. J., 2009: Nitric oxide and superoxide anion differentially activate poly(ADP-ribose) polymerase-1 and Bax to induce nuclear translocation of apoptosis inducing factor and mitochondrial release of cytochrome C after spinal cord injury. J. Neurotrauma, 26, 965-977.

73. Xu, J., Fan, G., Chen, S., Wu, Y., Xu, M., Hsu, C. Y., 1998: Methylprednisolone inhibition of TNF-alpha expression and NF-KB activation after spinal cord injury in rats. Brain Res. Mol. Brain Res., 59, 135-142.

74. Ying, Z., Roy, R.R., Edgerton, V.R., Gómez-Pinilla, F., 2005: Exercise restores levels of neurotrophins and synaptic plasticity following spinal cord injury. Exp. Neurol., 193, $411-419$ 
75. Zaki, F. A., Prata, R.G., 1976: Necrotizing myelopathy secondary to embolization of herniated intervertebral disk material in the dog. J. Am. Vet. Med. Assoc., 169, 222-228.

76. Zhou, X., He, X., Ren, Y., 2014: Function of microglia and macrophages in secondary damage after spinal cord injury. Neural Reg. Res., 9, 1787-1795.
77. Zhu, H., Feng, Y.P., Wise, Y., Yon, S. W., Shen, X. F., Liu, Y.S., et al., 2008: Early neurosurgical intervention of spinal cord contusion: an analysis of 30 cases. Chin. Med. J., 121, 2473-2478.

Received February 14, 2018

Accepted April, 15, 2018 